\title{
Nip, Tuck and Click: Medical Tourism and the Emergence of Web-Based Health Information
}

\author{
Neil Lunt ${ }^{*}, 1$, Mariann Hardey ${ }^{2}$ and Russell Mannion ${ }^{1}$ \\ ${ }^{I}$ The York Management School, University of York, York, UK \\ ${ }^{2}$ Department of Sociology, University of York, York, UK
}

\begin{abstract}
An emerging trend is what has become commonly known as 'Medical Tourism' where patients travel to overseas destinations for specialised surgical treatments and other forms of medical care. With the rise of more affordable cross-border travel and rapid technological developments these movements are becoming more commonplace. A key driver is the platform provided by the internet for gaining access to healthcare information and advertising. There has been relatively little attention given to the role and impact of web-based information to inform Medical Tourism decisions.
\end{abstract}

This article provides a brief overview of the most recent development in Medical Tourism and examines how this is linked to the emergence of specialized internet web sites. It produces a summary of the functionality of medical tourist sites, and situates Medical Tourism informatics within the broader literatures relating to information search, information quality and decision-making.

This paper is both a call to strengthen the empirical evidence in this area, and also to advocate integrating Medical Tourism research within a broader conceptual framework.

\section{INTRODUCTION}

The impact of globalisation in health and health care have paralleled emerging trends towards increased reliance upon individualised healthcare provision and 'consumer'-led access to 'health-related' internet sites [1]. The subsequent opening up of global markets has resulted in new demands and need for access to 'medical information', including information about international and cross-border provision of health care services. In response, there has been reform of the more traditional Government or State led healthcare provision that today extends beyond the notion of 'local citizenship' and 'community participation' as healthcare in the United Kingdom [2]. These developments include the growth of cross-border supply of health-related goods and services, greater overseas investment in domestic provision, increased movement of professionals and health providers, as well as trends towards consumption abroad and discounted travel incentives included as part of medical assessment and treatment [3-6]. One increasingly popular form of consumer expenditure is what has become commonly known as 'Medical Tourism'. This denotes what are typically elective procedures driven by patients being more able - and willing - to travel to overseas destinations for specialised surgical treatments and other forms of medical care. In recent years there has been heightened media coverage and anecdotal evidence of these new forms of patient or 'consumer' mobility where individuals travel outside their own country of residence for the consumption of health care abroad [7-11]. However, to date there has been relatively little attention given to the role and impact of webbased information to inform Medical Tourism decisions.

*Address correspondence to this author at the York Management School, University of York, UK; E-mail: n1517@york.ac.uk
Medical Tourism is not a new phenomenon. In terms of cross-border travel for health care there is a long history including the use of spas and wellness tourism that gained a mass market throughout eighteenth and nineteenth century Europe [12-14]. Traditionally, consumers from all continents and forms of health systems have travelled abroad for their healthcare to avoid waiting lists or access state-of-the-art techniques and receive better aftercare services [15]. With the rise of more affordable cross-border travel, rapid technological developments (encompassing both surgical techniques as well as the increased volume and access to 'quality' medical information on the internet) these transactions are becoming more frequent and potentially serve as a wide consumer market [16].

A key driver in the Medical Tourism phenomenon is the platform provided by the internet for gaining access to healthcare information and advertising. The aim of this article is to provide a brief overview of the most recent development in Medical Tourism and to examine how this is linked to the emergence of specialized internet web sites. In so doing the intention is to situate this emergent field of inquiry within the broader e-health literature. Despite the growth in the number of websites related to Medical Tourism there is currently a dearth of empirical evidence on the role, use and impact of these websites on the behaviour of health care consumers. This paper is in part a call to strengthen the empirical evidence in this area, and also to advocate integrating Medical Tourism research within a broader conceptual framework.

The paper is structured into four sections and is organized as follows:

- An overview of the growth and role of Medical Tourism in modern health care; 
- A review of Medical Tourism websites and the development of a conceptual framework to understand these;

- A consideration of the broader literatures pertinent to the internet and Medical Tourism;

- An empirical agenda for understanding Medical Tourism and the internet.

\section{OVERVIEW OF MEDICAL TOURISM LITERATURE}

Medical Tourism takes place when individuals opt to travel overseas with the primary intention of receiving medical (usually elective surgery) treatments. These journeys may be long-distance and intercontinental, for example, from Europe to Asia, and a range of treatments including dental care, cosmetic surgery, elective surgery, and IVF [17]. Medical Tourism involves exchanges that may include patients travelling from developed countries to other developed countries; patients travelling from developed countries to other developing countries; patients travelling from developing countries to developed countries; and patients from developing countries to other developing countries. Regions and countries particularly active in the delivery of Medical Tourism services include Asia (Malaysia, Thailand, Singapore, and Hong Kong); Eastern Europe (Hungary and Poland); Mediterranean (Malta and Cyprus); Africa (particularly South Africa); South and Central America (Costa Rica, Mexico, Brazil, and Cuba); and the Middle East (particularly Dubai and Jordon). Medical Tourism is embedded within the wider concept of patient mobility which encompasses a wide range of activities, including 'outsourcing', cross-border health collaboration, 'accidental tourists' and 'sunset migrants' [18].

A Medical Tourist may be defined in two ways depending on the form of health system and how it is funded. ${ }^{1}$ First, are Medical Tourists who can be categorised as 'consumers' because they use purchasing power expressed through the market to access a range of dental, cosmetic and elective medical treatment. There are related questions about access to insurance, the portability of insurance, and whether voluntary insurance systems include cover to the choice of overseas services. Within the United States, for example, some domestic private insurers have looked towards purchasing services overseas. In addition, there are also increasing numbers of consumers without insurance or who are under-insured and who look to pay out of pocket for treatments [19-21].

Second, at a European level, Medical Tourism may involve citizenship rights in order to receive medical surgery in another EU member state and request that their national purchaser reimburse the costs of the treatment (see European Court of Justice judgements including Case C-372/04 (The Watt case. 2005); also Case C-158/96 (The Kohll Case, 1998); and Case C-120/95 (Decker Case, 1998)). This established that internal market provisions allowed citizens of EU member states to access health in EU member

'An alternative division or categorisation of 'patients' could identify what is 'consumer' behaviour:

- Elective intervention seekers - e.g. cosmetic surgery etc.

- Non-elective seekers e.g. hip replacement etc. countries. The current European Commission's proposal for a Directive on Patients' Rights in Cross-border Health Care arose as the result of several European Justice Court rulings over patient mobility and the rights of patients to be reimbursed for treatments received in another EU country. Whilst it is clear that Member states remain primarily responsible for the delivery of their health care, this responsibility notwithstanding, the Directive outlines that the insured "...will not be prevented from receiving health care in another Member State... (and in the event of consumption of care from abroad,) the Member State of affiliation shall reimburse the costs to the insured person, which would have been paid for by its statutory social security system had the same or similar health care been provided in its territory" [22]. The Directive is subject to ongoing debate and its impact is currently unclear but it may effectively offer a form of voucher whereby citizens may seek health care in another EU Member State and be reimbursed up to the same amount of treatment costs within their home country. European patients may also be consumers - paying out of pocket or drawing upon private voluntary health insurance to fund Medical Tourism. These dual roles of citizen and consumer set Europe apart from the United States situation where Medical Tourists are more accurately described as a consumer rather than citizen [23].

The precise number of Medical Tourists making selffunded journeys is unknown ${ }^{2}$, but the number of UK Medical Tourists has been estimated at about 50,000 per annum [24]. Of these 50,000 Medical Tourists, about 20,000 are said to be seeking medical treatment, 14,500 cosmetic treatment, and 9,000 for elective surgery (including hip, knee and eye surgery), whilst a further 5,000 undertake fertility treatments overseas. In terms of the global health tourism market there are ongoing debates about the precise numbers seeking treatment. A McKinsey report estimated the number of Medical Tourists at 60-80,000 [16], whilst Youngman [25] takes a far more expansionist definition and puts the number at 5 million overall (including day surgery, cross-border exchanges, and developments outside of the United States).

\section{MATERIALS AND METHODOLOGY: REVIEW OF MEDICAL TOURIST WEBSITES}

Within the field of health care, the internet provides a range of options for accessing information relating to professional diagnosis, self-diagnosis, aftercare and support. This includes the possibility of obtaining a second opinion; to allow the patient to access further information; to promote the purchase of diagnosis services and treatments; and the development of support groups around conditions. The internet offers a range of functionalities and formats including discussion forums, file sharing, posting information and sharing experience, member only pages, advertisements and online tours.

The internet also facilitates decisions regarding the purchase of treatments. At the heart of the growth in Medical Tourism lies commercialization and in some part this is premised on the availability of web-based resources to furnish the consumer with information, advertisements and

\footnotetext{
${ }^{2}$ Whilst national authorities keep records of publicly funded transactions and exchanges (e.g. pan-European transfer), forms of out of pocket medical tourism are more difficult to capture.
} 
market destinations, and to connect consumers with an array of healthcare providers and brokers. Given the potentially pivotal place of web-based resources there are important questions about their role and function including: the types and availability of information provided; information provenance and quality; patient confidentiality; and how information provided over the internet shapes patient choice of treatment, provider and destination. In brief, how does the searcher (or surfer) become a consumer of health treatments abroad? "The Internet is altering how people consume health care, the way in which they obtain information and the manner in which they evaluate [treatment] alternatives" [26]. For Medical Tourism the truth of this statement is tempered by the need to advance our understanding of the internet's role in facilitating access to treatments.

\section{RESULTS}

There has been a burgeoning of sites dedicated to providing information for Medical Tourists in recent years, and in the sections below we provide an overview of such sites, identifying their characteristics. We restrict our coverage to English language web sites. Our preliminary review suggests the following typology of websites can be drawn: i) portals ii) media sites iii) consumer-driven sites iv) commerce-related sites, and v) professional contributions. These are each discussed in turn below.

\section{Portals}

- Open portals provide an entry point to many Medical Tourist destinations (including a range of countries and treatments). They allow individuals the opportunity to search for treatments, explore providers and to compare costs amongst the plethora of providers. For example www.treatmentabroad.co.uk and www.placidway.com/

- Regional portals provide a gateway to treatments and countries for a particular region, for example Asian countries. For example www.healthtourisminasia.com/

- National portals are sites that focus on treatments within one country, sometimes supported by a Government Department and seen as part of a broader economic development agenda. They may also have the support and sponsorship of travel organizations and the national tourism industry. For example: www.treatmentin hungary.net and www.medicaltourismofcostarica.com

Government portals exist where the national government has taken responsibility to develop Medical Tourism and has sponsored an organization to take this forward (e.g. in Singapore under the auspices of a state-supported body 'Singapore Medicine' see www.singaporemedicine.com).

- Treatment portals provide information around particular treatments (e.g. dentistry or IVF) and allow individuals to search different providers and compare costs between providers for different treatments including www.ivfinfo.net/ivf.html for IVF services, and www.healthtour.co.uk for dental treatment in Poland.

Provider portals focus on treatments offered by a small group of providers, perhaps within a single city such as Prague or Budapest. Provider portals may focus on a single provider or group (e.g. a surgery or hospital) and provide information and details about the facilities, treatments on offer, and the training and experience of staff. For example http://www.medth. $\mathrm{com} /$ focused on Marbella, www.beautyinprague.com centring on Prague, whilst www.bumrungrad.com/ details a major Thai provider of services.

Some sites may serve more than one function and these categories are not mutually exclusive. Portals use a range of technical functions including providing videos of treatments, virtual tours of facilities, patient testimonials, and details of the establishment, staff qualifications and professional experience. A key distinguishing characteristic of these sites is that they provide the potential consumer with opportunities to receive further information and compare a range of quotes for treatments. The portals share a common site structure: main header with branding and navigation; primary services and image; advertisements; related links and highlighted features; main content area with images, text and links; and a footer with contact and communication links.

\section{Media}

An increasing number of sites support the growing 'media' presence and associated marketing of Medical Tourism, and providing services beyond simple gateways to treatments. For example, sites showcase European and International Medical Tourist Associations, offering generic and provider information on the range of providers, facilitators and insurance options. There are also sites supporting Medical Tourist magazines and commercial interests involved in broader marketing and 'infomercial' services. These include stories and interviews with industry interests and details of emerging markets and new developments (for example the International Medical Tourism Journal www.imtjonline.com and Medical Travel Today www.medicaltraveltoday.com.

\section{Consumer}

Consumer-generated sites are available including:

- Medical Tourism blogs produced by both lay interests and professionals: www.medicaltourismblog.org/, www.healism.com/blogs/ and www.implant.uk.com/

- Discussion boards and debates where information is posted on the issues and experience of Medical Tourism.

\section{Commercial-Related}

Given that Medical Tourism arises from increased commercialization in the health sector, it is unsurprising that a number of sites provide information on commerce allied to Medical Tourism including:

- Overseas property sales sites emphasizing how the particular geographical areas are linked with the development of Medical Tourism (for example, Turkey, Costa Rica and Cyprus).

- Within money-saver, cost comparison sites and financial advice sites Medical Tourism may be listed as another product. 
- Travel insurance products available for Medical Tourism trips.

- Market research sites offering research and analysis reports and data relating to the Medical Tourist industry and emerging markets (typically requiring separate payment and subscription).

\section{Professional}

Finally there are professional and policy sites that provide information around Medical Tourism (e.g. the centrally-funded Department of Health in the UK, or advice from the British Association of Plastic, Reconstructive and Aesthetic Surgeons).

\section{What is it Medical Tourism Sites Do?}

Medical Tourism sites perform a range of functions, first and foremost the scope of the site is to introduce and promote services to the consumer. The main functionalities of the sites can be separated into five main processes that are arranged as a functionality of the site, promoted overtly through direct advertisement or sign-up services. These include functionality as a gateway to medical and surgical information, connectivity to related health services, the assessment and/or promotion of services, commerciality and opportunity for communication. This can be summarised in Table 1.

The range of Medical Tourism sites and related content raise familiar concerns associated with unregulated on-line health information [28]. The sites are relatively cheap to set up and run, and contributors may post information without being subject to clear quality controls. A contextual deficit means selective information may be presented, or presented in a vacuum, ignoring for example issues such as postoperative care and support. There is also the possibility of unreliable products being marketed via the internet - poor quality surgery or inadvisable treatments, unnecessary and even dangerous treatments. Indeed from Table $\mathbf{1}$ we can surmise that whilst Web 2.0 tools have, in effect, made it 'easier' to search and retrieve sources of medical information this needs to be evaluated against a need to continually 'assess' the quality of the sites, and the negotiation of the traditional 'patient'/'doctor' relationship, now as 'consumer'/'medical supplier' association connection. Thus, the experience of what it means to be a 'patient' is changing [29]. As a medical consumer there is empowerment through the active engagement of his/her health and wellness management. Moreover, health consumers have the opportunity to share treatment experiences with other patients, medical professionals and drug companies (e.g. the United States based PatientsLikeMe ${ }^{3}$ ). This has implications for the sharing of medical and health data. Privacy and data protection is an issue where technology allows information to be easily stored, retrieved, updated, accessed and exchanged. Here the emphasis is on individuals to:

\section{$>\quad$ Take responsibility for his/her own health information \\ $>\quad$ To publically share health information with others \\ $>\quad$ To individually assess health resources}

\footnotetext{
${ }^{3}$ www.patientslikeme.com/
}

To extract without delay and at minimal cost relevant health information.

\section{DISCUSSION: MEDICAL TOURISM AND RELEVANT LITERATURES}

The rise of Medical Tourism internet sites begs a number of policy-focussed research questions. These include:

- Who uses the sites and why?

- The nature of information search?

- The quality of information?

- How information influences decision-making?

- What are the implications of the majority of sites being commercially-driven?

\section{User Profile}

Very little is known about which consumers use webbased resources for Medical Tourism. Attempts to outline the size and socio-demographic profile of Medical Tourists $[16,21,25]$ do not go as far as examining how individuals source information. However, the development of both the industry itself (via marketing and advertising), and decisions about prospective regulation require far greater understanding of these very sources. Interrelated questions concern the profile of those searching for information on Medical Tourist treatments and provision: who makes use of web searches? What are their particular socio-demographic characteristics? What expectations do they have when conducting their searches? How do those searching for online information compare with Medical Tourists who access treatments via alternative routes, for example print media and through personal networks and referral?

\section{Information Search}

The internet presents a wealth of opportunity to access unlimited information which brings its own dilemmas. As Sheehan [30] notes:

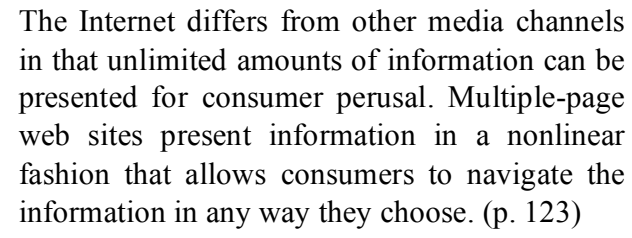

For those individuals who use the internet to gather information about Medical Tourism destinations, products and providers there are questions about how these consumers search and the types of website they visit. Evidence from elective medicine, for example, identifies that online searches by consumers involves a heavy reliance on search engines, and that interested searchers usually do not go beyond the front page once they had retrieved search results [31-32]. In one study, visits were restricted to a maximum of 10 websites [32]. Within the sphere of Medical Tourism we know little about search strategies, the use of the search terms, whether individuals seek out particular destinations and treatments, and how they judge and compare sites. Anecdotal industry suggestions point to lay terms and concepts being primarily used by consumers in their search for information and treatments. Yet information is vital to ease navigation around sites and to provide a fuller picture of 
Table 1. Table Summary of Functionality of Medical Tourist Sites

\begin{tabular}{|c|c|c|c|c|}
\hline Information & Connectivity & Assessment & Commerciality & Communication \\
\hline $\begin{array}{l}\text { To be seen to provide a } \\
\text { range of health } \\
\text { resources. } \\
\text { The link to information } \\
\text { on Medical Tourists } \\
\text { sites is usually via a } \\
\text { keyword web search, } \\
\text { such as Google, e.g. } \\
\text { 'surgery overseas', } \\
\text { 'breast augmentation' } \\
\text { etc. } \\
\text { The site content is to } \\
\text { encourage and assure } \\
\text { the consumer/patient } \\
\text { that they are making an } \\
\text { 'informed' and } \\
\text { independent choice(s) } \\
\text { about procedural } \\
\text { medical care, travel and } \\
\text { potential after care for } \\
\text { their treatment overseas. } \\
\text { Through these } \\
\text { provisions, the aim of } \\
\text { the medical tourist sites } \\
\text { is to have 'enough' } \\
\text { information to secure, } \\
\text { and be seen to support, } \\
\text { patient interest, in a } \\
\text { clear and easy to } \\
\text { understand layout. }\end{array}$ & $\begin{array}{l}\text { Medical Tourism sites } \\
\text { offer related information } \\
\text { to insurance brokers, } \\
\text { travel partners and other } \\
\text { medical websites. These } \\
\text { can include official } \\
\text { sources such as clinical } \\
\text { and public health } \\
\text { systems for a particular } \\
\text { country and/or be purely } \\
\text { commercial/ privatized. } \\
\text { One issue is limited } \\
\text { health service integration } \\
\text { (especially cross- } \\
\text { country) where the } \\
\text { promotion of consumer } \\
\text { services may be } \\
\text { prioritized over official } \\
\text { organizations, } \\
\text { institutions and cross- } \\
\text { country legislation. }\end{array}$ & $\begin{array}{l}\text { A key element to the } \\
\text { functionality of the } \\
\text { Medical Tourism sites is to } \\
\text { attract and sustain } \\
\text { consumer interest. The } \\
\text { assessment of the reliability } \\
\text { and validity of the } \\
\text { information and site } \\
\text { content can be (largely) } \\
\text { unregulated - particularly } \\
\text { where sites are 'outside' of } \\
\text { resident country domains. } \\
\text { This means that content } \\
\text { can be unclear, incomplete } \\
\text { and misleading [27]. } \\
\text { Moreover, the individual } \\
\text { assessment of information } \\
\text { and related health portals is } \\
\text { made more uncertain when } \\
\text { it is unlikely that content is } \\
\text { based on the systematic } \\
\text { review of medical care, } \\
\text { knowledge and procedures. } \\
\text { This means that the } \\
\text { assessment of site content } \\
\text { is only as 'good' or reliable } \\
\text { as the authors declare, and } \\
\text { the ability of the consumer } \\
\text { to navigate and evaluate } \\
\text { information. }\end{array}$ & $\begin{array}{l}\text { The commerciality of Medical } \\
\text { Tourism sites is built on the } \\
\text { profiling/data gathering of the } \\
\text { individual as they navigate sites. } \\
\text { Key data is obtained in the form } \\
\text { of cookies, surveys, newsgroup } \\
\text { postings and web forums. } \\
\text { Further data is also obtained and } \\
\text { secure when the consumer is } \\
\text { encouraged to sign up to } \\
\text { newsletters or to register with } \\
\text { the site to access the full } \\
\text { content. } \\
\text { In terms of functionality, this is } \\
\text { about the provision of services } \\
\text { and elective procedures, rather } \\
\text { than reliable source of medical } \\
\text { information. }\end{array}$ & $\begin{array}{l}\text { In terms of communication } \\
\text { Medical Tourist sites usually } \\
\text { facilitate a traditional } \\
\text { 'paternalistic' model of } \\
\text { relationships. This establishes } \\
\text { distance between those who } \\
\text { are the 'medical professionals' } \\
\text { and the 'patient' as a } \\
\text { consumer. } \\
\text { In addition, the direct } \\
\text { communication and/or } \\
\text { assessment of a } \\
\text { procedure/patient health is } \\
\text { often via a gate-keeper or } \\
\text { mediator. } \\
\text { In this way, the direct access } \\
\text { to a medical professional and } \\
\text { assessment is being reformed, } \\
\text { and there is a problem with } \\
\text { identifying the official } \\
\text { owner/keeper of sites. }\end{array}$ \\
\hline
\end{tabular}

how Medical Tourism is conceptualized and processes of consumer decision-making.

\section{Information Quality}

Given a large amount of materials around Medical Tourism is sourced on line this raises questions about information quality. Clear evidence from other studies suggests that the quality of health information online is variable and should be used with caution. Eysenbach and colleagues [33] found 79 studies that explored the quality of consumer health information - with the most frequently used criteria being accuracy, completeness, readability, design, disclosure and references but they noted that $70 \%$ of these identified a problem with quality. There is evidence that the quality of online information continues to vary widely. When the Journal of the American Medical Association standards for responsible print were adopted in order to judge the quality of infertility resources on the web, information was found to be at best variable [34]. Studies examining the quality of smoking cessation websites [35] and smoking cessation treatment on the internet [36] explored the content, quality and usability and concluded that those who seek Internet based advice on smoking cessations may have difficulty distinguishing between the numerous sites available and assessing their quality. Khazaal et al. [37] explored web-based information regarding social phobia, and concluded that the quality of sites was 'poor'. ${ }^{4}$ A study of the

${ }^{4}$ It did however suggest that the HON label was a good indicator of quality. For HON there is the requirement that sites be: authoritative, complementary to existing doctor-patient relations, protective of privacy, attributive, justifiable, transparent, financial disclosure, and clearly distinguish advertising policy from editorial content. content and physical properties of sites aimed at providing information around Attention Deficit Hyper-activity Disorder identified a range of issues: the use of safety data, site disclaimers, authorship, advertising, and instances of wrong or misleading information [32]. In the field of cosmetic surgery, a study using the search term 'breast augmentation' located 130 sites and concluded that $34 \%$ of these sites contained information that was either false or misleading [38]. Gordon et al. [39] examined the quality of plastic surgery information concluding "it is difficult for the average lay person to get authoritative information quickly and easily on at least one aspect of cosmetic surgery." (p. 175).

Given the evident variability in quality, one response has been to attempt to develop tools to assess the quality of online health information resources [40]. Indeed, the emphasis on evidence-based medicine has reinforced the role of Kite marks. However, their utility outside strictly clinical information remains uncertain - particularly when the same information is left 'open' to the public and is utilised for patient/client/consumer content. Thus, whether such tools have any salience, reliability, credibility and validity for Medical Tourism however remains unexplored. Can filters or frameworks identify Medical Tourism sites that are relatively poor or provide misinformation? Similarly, tools that have been developed elsewhere in areas of health information provision, e.g. templates developed for assessing print information transferred to web based resources, have not been explored vis-à-vis Medical Tourism [41]. Charnock and Shepperd [42] for example, examine the application of DISCERN (a tool for assessing the quality of health information on the internet) to online material and conclude 
that such a scheme can provide flexible skills and possibilities of transferability because of the shared emphasis on the content of written treatment information. Shepperd et al. [43] conclude that a single quality score calculated on answers to DISCERN can be used to support a simple threshold to assess whether good quality information is provided. Griffith and Christensen [44] suggest DISCERN can be used by consumers, and consumer organizations interested in assembling links to high quality sites [also, 45]. Provost et al. [46] attempt a comprehensive and standard quality assessment for health sites, developing an instrument that they assess can be used by consumers, researchers, and health care professionals: "The scale may also be used in the decision-making process of webmasters or editorial boards in selecting links to be posted on their web sites" (p. 49).

Such tools may lead to quality markers being laid down and in relation to quality markers: "Research shows that consumers are more receptive to websites produced by governments or professionals for health information..." [32]. Eysenbach and colleagues [33] contend however it is difficult to develop objective criteria to assess the quality of health information websites. This they argue is because of complexities surrounding the precise relationship between quality indicators and the actual quality of information. Similarly, Bernstam et al. [47] maintain that it may be difficult to apply quality criteria and that often inter-rater reliability is not given for any particular instrument [see also $1]$.

Such evidence begs the questions of how (if at all) the quality of Medical Tourism information is best addressed: ranging from codes of conduct, self taken quality labels, user guidance tool, third party quality and accreditation labels, to educating users and assisting those wishing to search. The education of site providers may be further attempts to assure quality [40]. There are also possibilities of gateway sites and evaluation instruments [48]. Of course, the view could be taken that no quality assurance is required beyond a simple caveat emptor - 'buyer beware'.

\section{Decision-Making}

Important questions persist around how consumers process the information they retrieve from website searches, how they take into account commercial interests and bias, and how this all contributes towards decision making. Again there is not yet direct research evidence for Medical Tourism and this requires remedy. There is some evidence from breast augmentation patients use of the internet with one survey suggesting that $68 \%$ of respondents utilized internet information, and of this subset of patients the information influenced decision making around choice of procedures (in $53 \%$ of cases), choice of surgeon (36\% of cases) and choice of hospital (25\% of cases) [49]. Elsewhere, Peterson et al. [31] suggest consumers of medicine are aware of issues around bias, commercialization and lack of regulation when they explore health sites, but suggest that the context of what is being searched is important. They argue that commercial considerations "may have an impact on the motives for and quality of information". What is unclear for example is whether potential consumers purposively seek information that cautions about possible pitfalls and difficulties (perhaps through professional or regulatory sites), as well as some of the more aesthetic and clinical attractions of Medical Tourism. We need to know far more about how individuals accessing Medical Tourist information judge the information they retrieve given such information may be confusing, overwhelming, and even contradictory. An important distinction is likely to exist between how consumers actually conduct searches and reach decisions from what they say they do. For instance, Bates et al. [50] note that while consumers may report that they use source credibility to judge information quality, observational studies would suggest this is rarely borne out in practice [see also 31]. Marshall and Williams [51] look at ways that health information is assessed by consumers and recommend public awareness of critical appraisal tools, developing information literacy for health, and health information access points.

Underpinning the search and interpretation of sites is the fundamental issue of how trust and credibility of information are established and maintained given there are limits of choice, the existence of uncertainty and the possibility of pain incurred by treatments [52]. Here there are potential conceptual frameworks that can guide our analysis such as O'Grady's work developing a framework of presumed, earned, surface and reputed credibility in relation to assessing websites [53]. There is clearly a need for empirical work on Medical Tourism to be able to advance such conceptual developments.

Much medical tourism information is presented alongside images of the 'body beautiful' and associated with 'successful surgery', youth and vigor. Such images reflect the broader medicalisation of lifestyles or way of life around a 'healthism' that is assumed to prevent illness and to signal wellness [54]. Medical tourist sites aim to perform roles of influencing cognitive, affective and behavioural dimensions of consumers. Many sites seek to raise awareness of Medical Tourism, create a perceived need, and ensure the consumer is motivated to purchase. ${ }^{5}$ There is, however, a major imbalance between the types of site identified in our typology, with most information being gleaned from portals with clear commercial imperatives. Concerns raised by the British Association of Plastic, Reconstructive and Aesthetic Surgeons about the 'irresponsibility' of sales approaches to cosmetic surgery using billboard advertising may have parallels in web-based advertising [56]. How information is used in supporting intended cognitive, affective and behavioural shifts and how material is weighed alongside other forms of hard and soft intelligence (including media reports, professional networks, and friends and family) requires investigation. As Hardey [57] noted "Using the Internet is an inherently interactive process that involves users in a continual process of decision making" (p.825). The challenge is to understand the place of the internet in the dureé of the Medical Tourist encounter and decision-making.

\section{New Medical Encounters}

The relations of the internet and Medical Tourism lie beyond simply being a conduit for information. Writing has focused on how users educate themselves about medical

\footnotetext{
${ }^{5}$ Consumer brand knowledge may come from a range of sources: object reality (personal experience); constructed reality (advertising and media); and experiences of others (e.g. word-of-mouth). The combination of all these is the consumer integration process [55].
} 
conditions and the impact of such knowledge on the serviceencounter [58]. In the field of Medical Tourism consumers are both accessing information resources and also exploring a distribution channel for services. The internet promises to change the balance of power of patient-doctors and to effect new conceptualizations and layers of relationships including notions of consumerism, and consumer voice and exit in respect of patient choice [59]. In particular user, or consumer-generated information appears to be playing an increasingly important role [60]. One example is where consumers publish their reviews of named professionals and/or treatments that are directed at paid for medical services. For example, the United States based medical review site RateMD ${ }^{6}$ offers warnings about the practices of some doctors and dentists, whilst also recommending others [29]. This is what Eysenbach refers to as the role 'apomediaries' whereby filtering of information takes place downstream via ratings and social networks rather than utilizing traditional 'expert' intermediaries [61]. Such ratings and networks will not lead to clear and objective judgments of treatment quality, clinical outcomes and particular treatment risks.

Given the influence of advertising and the drive to commercialization there are longstanding questions relating to asymmetry of information, safety, and informed choice that link to Medical Tourism and the Internet. As many of the sites in our typology are primarily adverts and 'infomercials' (with a series of buttons, banners and popups), what sources exist that are non-commercial in nature and provide information as opposed to commercialization?

Within the UK healthcare has not traditionally been viewed as simply another product to be marketed and advertised. Advertising for medicinal products is strictly controlled by legislation and Codes of Practice [62, 63]. Non-prescription medicines may be advertised to the general public but only under particular conditions: for example advertisements must not imply that medical consultation is not necessary. There is a ban on Direct-to ConsumerAdvertising for prescribed medicines. For internet advertising the same rules hold as for other advertising forms:

\begin{abstract}
Promotional material directed to a UK audience provided on the internet is subject to the Code [Association of the British Pharmaceutical Industry Code of Practice]. However, as a matter of practice, enforcement remains an issue as far as the regulator are concerned as they are only able to enforce against entities with a presence in the jurisdiction [62, p.105].
\end{abstract}

Advertisements for prescription only medicines are acceptable on websites only when their nature and content is directed at health professionals [63, section 6.3]. The marketing of cosmetic surgery is commonplace in UK settings including billboards and the Committee on Advertising Practice has released guidance on the interpretation of rules in the British Code of Advertising [64].

\footnotetext{
${ }^{6}$ www.ratemds.com/
}

Parallel literature exploring Direct-to-Consumer Advertising in relation to advertising for pharmaceuticals, diet supplements, diagnostic tests and some surgery makes some interesting observations. Gollust et al. [65] examine the Direct-to-Consumer internet sales of genetic services and note that sites are likely to exaggerate benefits. Wolfberg [66] identifies genes testing available to consumers on the web; Datta et al. [67] explore the quality of websites marketing home diagnostic tests and conclude that the majority of websites provide information that is of inadequate quality. Illes et al. [68] focus on Direct-toConsumer advertising in print and information brochures, concluding that such materials fail to provide consumers with the sort of comprehensive and balanced information necessary for informed decision-making. They suggest it is common to identify misinformation, unsubstantiated scientific claims, fear provoking threats, and a lack of information on the uncertainties and the risks of particular services - in their case tomographic and magnetic resonance imaging. With regards to surgery, Salant and Santry [69] highlight the growth of web-based advertising of bariatric surgery centres. These centres - in common with many Medical Tourist destinations - rely on patient self-referral and thus need to stimulate demand for these services.

On-line information and on-line consultation within healthcare carry risks. In relation to online information, Wald and colleagues [70] suggest an emergent model of consultation that involves the interaction of patient-webdoctor may impact detrimentally on the patient-doctor relationship. Whilst there are potential advantages of information provision - informed choice, shifting power relations and improved information flows - drawbacks include the breakdown of the patient-doctor relationship. There are further issues associated with the worried well, information overload, raised expectations, unequal accessibility to information and poor quality information [71-73].

Online or remote consultation may be utilized for primary or secondary medical opinion [74]. Some research indicates that the advantages of remote consultation includes convenience and flexibility but acknowledge doctors lack detailed knowledge of medical and social history and are unable to perform a physical examination that lies at the centre of the medical encounter [74-75]. As Miller and Derse [76] suggest:
e-health sites and private practitioners now offer, without face-to-face contact, treatments that have long been considered the practice of medicine: access to prescription drugs, a single consultation with a physician who remains anonymous, and ongoing treatment of an identified patient by an identified physician ( $\mathrm{p}$. 162).

Advantages of access and ease of communication must be balanced against difficulties of judging quality, and a lack of clear regulatory oversight and reach: "the anonymity of physicians on many sites defies even an attempt at accountability and continuity of care' (p. 171) [76]. Online consultation en route to the prescription of drugs entails its own uncertainties [77]. In 2006 the United Kingdom's General Medical Council issued new guidance detailing the 
conditions for remote prescribing, emphasising the importance of patient-doctor dialogue, monitoring of progress and monitoring effectiveness of interventions, all of which are problematic with internet consultations and carry potential legal ramifications:

\begin{abstract}
Although the same level of "duty of care" as in a traditional doctor-patient relationship may not exist in an online consultation, a prescribing doctor will still be required to exercise a duty of care to prevent the loss or injury to a patient. A breach of that duty... leading to loss which is a direct and natural result of the breach... will result in liability for negligence (p. 8) [77].
\end{abstract}

These issues have not been studied in relation to Medical Tourism and the internet and the challenge is to understand these complex forms of consumer relationships and patient models that are being generated.

\section{CONCLUSION: TOWARDS AN EMPIRICAL AGENDA}

The final section of this review outlines the shape of an empirical research agenda on the role and use of Medical Tourism internet sites. The internet is inextricably linked with the rise and further growth of Medical Tourism and to that extent it is important to strengthen the evidence base in this area. To begin this process we outline a research agenda on the internet and Medical Tourism, sketching onto a template developed by Eysenbach $[78]^{7}$, and further developed to fit our own thinking.

- $\quad$ Evidence-based. There are questions about the extent to which sites are conduits for information on clinical quality, safety and other performance criteria that may support informed decision-making. For example, do sites include details of infection rates or clinical outcome measures? What is the breadth and depth of evidence available across institutions and clinicians? Further, how is such information presented in terms of treatment risk (positive or negative) and decisionmaking?

- Enhancing quality. How does the internet facilitate comparisons of providers across countries and in terms of price and quality? Does it provide a suitable mechanism to uncover weaker quality providers? To what extent and how is patient choice enabled by such processes?

- Efficiency. Does the internet lead to improved efficiency and reduced costs in relation to Medical Tourism? Does the internet allow straightforward search of providers and ease of information retrieval through portals, or is navigation problematic and

\footnotetext{
${ }^{7}$ Eysenbach's original suggestions were around:

- Efficiency (improve and reduce costs)

- Enhancing quality

- Evidence-based

- Empowerment of consumers and patients

- Encouragement of a new patient/professional relationship

- Education of physicians

- Enabling information exchange and communication

- Extending scope of health care beyond conventional

- Ethics

- Equity
}

hampered by information overload? Similarly, regarding particular portals, what is it that individuals find most helpful in being able to maneuver around sites?

- Empowerment of consumers and patients. In what ways and for what groups of consumers does the internet provide empowerment, and is this common across all forms of surgical treatment? Are those availing themselves to Medical Tourism enabled or encouraged to make more informed choices about treatments, tests or self-management? Alternatively, do they make less informed choices as 'health' information ultimately derives from many similar sources and is enmeshed in a process of supplierinduced demand whereby providers generate a demand for their own services.

- $\quad$ Encouraging new patient/professional relationships. In particular, how does the internet assist in configuring those participants into new market relations? Does Medical Tourism further reshape the doctor/patient relationships and in what ways [79]? Whilst choices and risk are increasingly individualized [80] does the internet and growth of Medical Tourism contribute towards individual health being wholly commercialized and commodified? Does it extend consumer preferences in the form of holding shadow budgets? In what ways is Medical Tourism reshaping the medical profession and does it provide a route to United States style medical market? In short, what are the boundaries of the health care consumer when seen through the viewfinder of Medical Tourism?

- $\quad$ Enabling information exchange and communication. In what ways does the internet provide innovative forms of exchange and communication, including developments within sites that are more transactional in allowing information and financial exchange? In light of these exchanges, how are we to understand privacy and thus potential risk to the confidentiality of patient information; how is this managed and perceived by both organisations and consumers? What are the potential and real issues of individuals volunteering personal information to providers of care - which is then used by marketing organizations and insurance providers?

- Extending the scope of health care beyond conventional. This includes new forms of health treatment and approaches to health and wellbeing. The search for untapped markets may allow new menus of surgical treatments and packages of treatment to be offered to consumers. Medical Tourism focuses on dentistry, cosmetic and elective surgery but also may embrace IVF treatments and organ transplantation. This may plausibly lead to increases in social/health divisions because those who have the resources (both purchasing power and web access) can use information to make choices that are not open to others. This may emerge as some may want to look more 'young', while others are seeking 'health treatment' to return to productive work. 
- Ethical implications arising from new forms of interaction. Such developments raise questions about whether citizens are being displaced with consumers, and elsewhere there are controversial dimensions such as transplant tourism [81-84]. Do these wider shores of Medical Tourism present ethical dilemmas and what are the implications of this for the internet?

- Equity considerations. Frequently the digital divide is signaled as a danger alongside e-health initiatives. Such a divide may be more complex for Medical Tourism with an inverse relationship where socioeconomic elites use personal networks and referral for treatments overseas, whilst lower income consumers seeking economy use the internet to source treatments. Similarly, does internet use/non-usage widen the scope of the patient choice agenda for some groups of patients compared to others? Do consumers use Medical Tourism to subvert national restrictions (eligibility, waiting lists) on medical treatment?

Europe. Whilst recognising that Medical Tourism is a global phenomenon there is a particular European perspective in respect of commerce, health policy, website quality, and safety. To take one instance - a recent European Union e-commerce directive (2000/31/EC) requires all companies to display ways in which the website can be contacted. The ECJ has ruled that this may include a telephone number and a contact form that is answered within an hour. The ruling impacts on e-business operating within the EU and requires: the name of service provider, the geographic address of the service provider, and service provider details including email address where they may be communicated with swiftly and effectively must be provided before a contract can be entered into via the website.

\section{SUMMARY}

New forms of patient or 'consumer' mobility, whereby individuals travel outside their own country of residence to receive medical treatments are receiving growing media attention. Helping to drive this growth in Medical Tourism is the role of the internet which provides a conduit for information, advertising and purchasing arrangements. To date however there is a dearth of empirical evidence on the role, use and impact of these websites on the behaviour of health care consumers.

In beginning to review Medical Tourism websites and advance a conceptual framework to better understand these developments this paper takes tentative steps towards a broader research agenda. Interrelated questions include: who uses the sites and why; the nature of information search; the quality of information; how information influences decisionmaking; what are the implications of the majority of sites being commercially-driven? The agenda is one that encompasses health management, health informatics, patient and consumer decision-making, and health marketing. In tackling these questions, it is our intention that a multidisciplinary approach drawing on established literatures and aspiring to theoretically-informed knowledge will provide the best route forward.

\section{ACKNOWLEDGEMENTS}

We would like to thank the anonymous referees for their helpful comments. Thanks are also due to Dr Percivil Carerra for discussions and collaboration which helped shape material included in the early sections of this paper.

\section{REFERENCES}

[1] Craigie M, Loader B, Burrows R, Muncer S. Reliability of health information on the internet: an examination of experts' ratings. J Med Internet Res 2002 Jan-Mar; 4(1) [accessed February 2009] Available from: URL: http:/www.pubmedcentral.nih.gov/articler ender.fcgi?artid=1761929

[2] Milewa T, Valentine J, Calnan M. Community participation and citizenship in British health care planning: narratives of power and involvement in the changing welfare state. Sociol Health Illn 1999; 21(4): 445-65.

[3] Smith RD. Foreign direct investment and trade in health services: a review of the literature. Soc Sci Med 2004; 59(11): 2313-23.

[4] Holden C. The internationalization of corporate healthcare: extent and emerging trends. Compet Change 2005; 9(2): 185-203.

[5] Blouin C, Drager N, Smith R, Eds. International trade in health services: debates on the GATS. Washington DC: World Bank, 2005.

[6] Smith RD, Chanda R, Tangcharoensathien V. Trade in healthrelated services. Lancet 2009; 373(9663): 593-601.

[7] Bridge M. Medical tourism; the pros and cons. The Times, October 13, 2007.

[8] Britten N. Patients go abroad as dentists' fees soar. Telegraph, January 11, 2008.

[9] Hussain A. In search of sun, sand and surgery. The Sunday Times, August 26, 2007

[10] Leafe D. Health tourism: have your eyes done, then see the fjords. Telegraph, October 20, 2008.

[11] Moore A. Health tourism: don't forget your toothbrush. Health Serv J, January 12, 2009.

[12] Porter R. The medical history of waters and spas: introduction. Med Hist Suppl 1990; 10: 7-12.

[13] Hembry PM. The English spa, 1560-1815: a social history. London: Athlone Press; 1990.

[14] Smith M, Puczkó L, editors. Health and wellness tourism. Oxford: Butterworth-Heinemann/Elsevier; 2008

[15] Goodrich JN. Socialist Cuba: a study of health tourism. J1 Travel Res 1993; 32(1): 36-41.

[16] Ehrbeck T, Guevara C, Mango PD. Mapping the market for medical tourism. McKinsey Q May 2008; pp. 1-11.

[17] Connell J. Medical tourism: sea, sun, sand, and ... surgery. Tourism Manag 2006; 27(6): 1093-100.

[18] Bertinato L, Busse R, Fahy N, et al. Cross-Border Health Care in Europe. Policy Brief, WHO on behalf of the European Observatory on Health Systems and Policies, Denmark 2005.

[19] Milstein A, Smith M. America's new refugees - seeking affordable surgery offshore. Proc Counc Mass Med Soc 2006; 355(16): 163740.

[20] Repasky M. A cut below: Americans look abroad for health care http://abcnews.go.com/Business/IndustryInfo/story?id=2320839\&p age $=1$. August 29, 2006 [Accessed July 2009].

[21] Deloitte Center for Health Solutions. Medical tourism; consumers in search of value. Deloitte; 2008. Available from: URL: http://www.deloitte.com/dtt/cda/doc/content/us_chs_MedicalTouris mStudy(1).pdf

[22] European Commission. A proposal for directive on patients' rights in crossborder healthcare. Brussels (IP/08/108); 2 July 2008.

[23] Eysenbach G. Consumer health informatics. Br Med J 2000; 320: 1713-6.

[24] Treatment Abroad (2007) www.treatmentabroad.com/about/med ical-tourism-survey/ [Accessed June 15, 2009].

[25] Youngman I. Medical tourism statistics: why McKinsey has got it wrong. Intl Med Travel Jl 2009. Available from: URL: http://www.imtjonline.com/articles/2009/mckinsey-wrong-medicaltravel/

[26] Miller EA, West DM. Characteristics associated with use of public and private web sites as sources of health care information. Med Care 2007; 45, (3): 245-51. 
[27] Ibraghimova I. Critical assessment of internet medical information (Tech Topic \#10). 2006 Posted January 9th, 2007 by GN, [retrieved July, 2009]. Available from: URL: http://www.lrcnetwork.org/tt10e

[28] Eysenbach G. An ontology of quality initiatives and a model for decentralized, collaborative quality management on the (semantic) world wide web. J Med Internet Res 2001; 3(4): e34. Available from: URL: http://www.jmir.org/2001/4/e34/HTML

[29] Hardey M. Consuming professions: user-review websites and health services. Forthcoming.

[30] Sheehan KM. Direct-to-consumer (DTC) branded drug web sites. J Advert 2007; 36(3): 123-35.

[31] Peterson G, Aslani P, Williams KA. How do consumers search for and appraise information on medicines on the Internet? A qualitative study using focus groups. J Med Internet Res 2003; 5(4): e33. Available from: URL: http://www.jmir.org/2003/4/ e33/HTML

[32] Akram G, Thomson AH, Boyter AC, Morthon MJS. Characterisation and evaluation of UK websites on attention deficit hyperactivity disorder. Arch Dis Child 2008; 93: 695-700.

[33] Eysenbach G, Powell J, Kuss O, Sa E-R. Empirical studies assessing the quality of health information for consumers on the world wide web: A systematic review. JAMA 2002; 287(20): 2691700 .

[34] Okamura K, Bernstein J, Fidler AT. Assessing the quality of infertility resources on the world wide web: tools to guide clients through the maze of fact and fiction. J Midwifery Womens Health 2002; 47(4): 264- 8

[35] Etter JF. A list of the most popular smoking cessation web sites and a comparison of their quality. Nicotine Tob Res 2006; 8(Suppl 1): S27-34.

[36] Bock BC, Graham AL, Sciamanna CN, et al. Smoking cessation treatment on the internet: content, quality, and usability. Nicotine Tob Res 2004; 6(2): 207-19.

[37] Khazaal Y, Fernandez S, Cochand BA, Reboh I, Zullino D. Quality of web-based information on social phobia: a cross-sectional study. Depress Anxiety 2008; 25: 461-5.

[38] Jejurikas S, Rovak JM, Kuzon WM, Chung KC, Kotsis SV, Cederna, PS. Evaluation of plastic surgery information on the internet. Ann Plast Surg 2002; 49(5): 460-5.

[39] Gordon J, Barot L, Fahey AL, Matthews MS. The internet as a source of information on breast reconstruction. Plast Reconstr Surg 2001; 107(1): 171-6.

[40] eEurope. Quality criteria for health related websites. J Med Internet Res 2002;4(3):e15. Available from: URL: http://www.jmir.org/ 2002/3/e15/HTML

[41] Charnock D. The DISCERN handbook: quality criteria for consumer health information. Abingdon(UK): Radcliffe Medical Press; 1998

[42] Charnock D, Shepperd S. Learning to DISCERN online: applying an appraisal tool to health websites in a workshop setting. Health Educ Res 2004; 19(4): 440-6.

[43] Shepperd S, Charnock D, Cook A. A 5-star system for rating the quality of information based on DISCERN. Health Info Libr J 2002; 19: 201-5.

[44] Griffiths KM, Christensen H. Website quality indicators for consumers. J Med Internet Res 2005; 7(5):e55. Available from: URL: http://www.jmir.org/2005/5/e55/HTML

[45] Griffiths KM, Christensen H. The quality and accessibility of Australian depression sites of the World Wide Web. Med J Aust 2002; 176 (suppl): S97-S104.

[46] Provost M, Koompalum D, Dong, D, Martin, BC. The initial development of the WebMedQual scale: Domain assessment of the construct of quality of health web sites. Int J Med Inform 2006; 75 : 42-57.

[47] Bernstam EV, Sagaram S, Walji M, Johnston CW, Meric-Bernstam F. Usability of quality measures for online health information: can commonly used technical quality criteria be reliably assessed? Int J Med Inform 2005; 74: 675-83.

[48] Breckons M, Jones R, Morris J, Richardson J. What do evaluation instruments tell us about the quality of complementary medicine information on the internet. J Med Internet Res 2008; 10(1): e3. Available from: URL: http://www.jmir.org/2008/1/e3/HTML

[49] Losken A, Burke R, Elliot F, Carlson GW. Infonomics and breast reconstruction: Are patients using the internet? Ann Plast Surg 2005; 54: 247-50.
[50] Bates BR, Romina S, Ahmed R, Hopson D. The effect of source credibility on consumers' perceptions of the quality of health information on the Internet. Inform Health Soc Care 2006; 31(1): 45-52.

[51] Marshall LA, Williams D. Health information: does quality count for the consumer?: How consumers evaluate the quality of health information materials across a variety of media. J Librar Inform Sci 2006; 38: 141-56.

[52] Natalier K, Willis K. Taking responsibility or averting risk. Health Risk Soc 2008; 10(4): 399-411.

[53] O'Grady L. Future direction for depicting credibility in health care web sites. Int J Med Inform 2005; 75: 58-65.

[54] Crawford R. Healthism and the medicalization of everyday life. Int J Health Serv 1980; 10(3): 365-88.

[55] Da Silva RV, Alwi SFS. Cognitive, affective attributes and cognitive, behavioural response in retail branding. J Product Brand Manag 2006; 15(5): 293-305.

[56] Carter H. Nip, tuck, hard sell: don't let ads seduce you, plastic surgeons warn. The Guardian, September 19, 2008.

[57] Hardey M. Doctor in the house: the internet as a source of lay health knowledge and the challenge to expertise. Sociol Health Illn 1999; 21(6): 820-35.

[58] Hogg G, Laing A, Winkleman D. The professional service encounter in the age of the Internet; an exploratory study. J Prof Serv Mark 2003; 17(5): 476-94.

[59] Hirschmann AO. Exit, voice and loyalty: responses to decline in firms, organizations, and states. Cambridge, Mass: Harvard University Press; 1970.

[60] Hardey M. Public health and Web 2.01. J R Soc Promo Health 2008; 28(4): 171-9.

[61] Eysenbach G. In: Kuhn KA, Warren, JR, Leong T-Y, Eds. From intermediation to disintermediation and apomediation: new models for consumers to access and assess the credibility of health information in the age of Web2.0, Studies in health technology and informatics MEDINFO 2007; Proceedings of the 12th World Congress on Health (Medical) Informatics 2007; 129: pp. 162-6.

[62] Williams A, Valverde S. England \& Wales. The international comparative legal guide to pharmaceutical advertising. London: Global Legal Group; 2009. p. 98-107.

[63] Medicines and Healthcare products Regulatory Authority. The blue guide: advertising and promotion of medicines in the UK. London: The Stationary Office 2005.

[64] Committee of Advertising Practice. Help note on cosmetic surgery marketing. London: CAP 2008.

[65] Gollust SE, Wilfond BS, Hull SC. Direct-to-consumer sales of genetic services on the Internet. Genet Med 2003; 5(4): 332-7.

[66] Wolfberg AJ. Genes on the web-direct-to-consumer marketing of genetic testing. Proc Counc Mass Med Soc 2006; 355(6): 543-5.

[67] Datta AK, Selman TJ, Kwok T, Tang T, Khan KS. Quality of information accompanying on-line marketing of home diagnostic tests. J R Soc Med 2008; 101: 34-8.

[68] Illes J, Kann D, Karetsky K, et al. Advertising, patient decision making, and self-referral for computed tomographic and magnetic resonance imaging. Arch Intern Med 2004; 194: 2415-19.

[69] Salant T, Santry HP. Internet marketing of bariatric surgery: contemporary trends in the medicalization of obesity. Soc Sci Med 2006; 62: 2445-57.

[70] Wald HS, Dube CE, Anthony DC. Untangling the web - the impact of internet use on health care and the physician-patient relationship. Patient Educ Couns 2007; 68: 218-24.

[71] Cox B. The impact of the internet on the GP-patient relationship. Inform Prim Care 2002; 10: 95-8.

[72] McCaw B, McGlade K, McElnay J. The impact of the internet on the practice of general practitioners and community pharmacists in Northern Ireland. Inform Prim Care 2007; 15: 231-7.

[73] Levy JA, Strombeck R. Health benefits and risks of the internet. J Med Syst 2002; 26(6): 495-510.

[74] Umefjord G, Petersson G, Hamberg K. Reasons for consulting a doctor on the internet: users of an Ask the Doctor service. J Med Internet Res 2003; 5(4): e26. Available from: URL: http://www.jmir.org/2003/4/e26/HTML

[75] Umefjord G, Hamberg K, Malker H, Petersson G. The use of an internet-based Ask the Doctor service involving family physicians: evaluation by a web survey. Fam Pract 2006; 23(2): 159-66.

[76] Miller TE, Derse AR. Between strangers: the practice of medicine online. Health Aff 2002; 21(4): 168-79. 
[77] George C, Duquenoy P. In: Duquenoy P, George C, Kimppa K, Eds. Online medical consultations: legal, ethical, and social perspectives. Ethical, legal, and social issues in medical informatics. London: IGI Global; 2008. pp. 1-28.

[78] Eysenbach G. What is e-health. J Med Internet Res 2001; 3(2): e20. Available from: URL: http://www.jmir.org/2001/2/e20/HTML

[79] Wiles R, Higgins, J. Doctor-patient relationships in the private sector: patients' perceptions. Sociol Health Illn 1996; 18(3): 34156.

[80] Bauman Z. The individualized society. Malden, MA: Polity Press 2001.
[81] Canales MT, Kasiske BL, Rosenberg ME. Transplant tourism: outcomes of United States residents who undergo kidney transplantation overseas. Transplantation 2006; 82(12): 1658-61.

[82] Budiani-Saberi DA, Delmonico FL. Organ trafficking and transplant tourism: A commentary on the global realities. Am J Transplant 2008; 8(5): 925-9.

[83] Scheper-Hughes N. Commodity fetishism in organs trafficking. Body Soc 2001; 7(2-3): 31-62.

[84] Scheper-Hughes N. Keeping an eye on the global traffic in human organs. Lancet 2003; 361(9369): 1645-8.

(C) Lunt et al.; Licensee Bentham Open.

This is an open access article licensed under the terms of the Creative Commons Attribution Non-Commercial License (http://creativecommons.org/licenses/by$\mathrm{nc} / 3.0 /$ ) which permits unrestricted, non-commercial use, distribution and reproduction in any medium, provided the work is properly cited. 